\title{
NuEvos ESPACIOS DE REPRESENTACIÓN POLÍTICA EN LA SELVA FRONTERIZA. LA DISPUTA POR LA REMUNICIPALIZACIÓN en Chiapas, MÉxico ${ }^{1}$
}

\author{
Luis Rodríguez Castillo²
}

\section{Introducción}

L as demandas por el reconocimiento de los derechos y la autonomía indígenas impulsados por el neozapatismo ${ }^{3}$ han tenido un importante impacto en la agenda política nacional, pues ha instalado en el centro del debate la composición pluriétnica de la nación. En este trabajo, antes que realizar un análisis general del neozapatismo o una documentación detallada de un estudio de caso, reflexiono acerca de las transformaciones que han surgido de manera diferencial en los espacios local y regional en la selva fronteriza de Chiapas. ${ }^{4}$ Esta región es aledaña a Las Cañadas de Ocosingo — la "zona de conflicto"Grupos políticos representativos de las posturas en pugna coexisten sobre los mismos territorios y ambos actores políticos buscaron impulsar su propia forma de reorganización territorial. Con ello, las demandas e iniciativas obtuvieron los matices propios de las reinterpretaciones locales.

El reconocimiento a los derechos y autonomías indígenas impulsado por el Ejército Zapatista de

Luis Rodríguez Castillo,CIESAS-Sureste
Liberación Nacional (EZLN) y sus simpatizantes fue la demanda que sirvió para legitimar las acciones de actores locales y regionales en el contexto de las respuestas operadas por parte de los gobiernos federal y estatal. El argumento central es que las opciones de reorganización territorial han abierto espacios de representación política en la región. Estos nuevos espacios pasan por los proyectos de autonomía de facto impulsada por el neozapatismo y por la instauración de municipios libres impulsados por el gobierno del estado. Es decir, en este trabajo me propongo analizar la transformación del espacio de relaciones sociales (Bourdieu, 1990) en la región selva-fronteriza de Chiapas, a partir de las posiciones y relaciones de los grupos políticos que definieron proyectos de organización territorial diferenciados.

El neozapatismo impulsó los municipios y regiones autónomas, mientras que la intervención estatal favoreció la instauración del municipio libre. Cabe destacar que constituyeron, una en relación con la otra, una "configuración territorial" contestada y vivida como "un hecho político, fruto del ejercicio e impugnación del poder" (Velázquez, 1997). Los procesos de construcción 
y redefinición de las territorialidades han transformado, entonces, el campo de relaciones políticas en el cual las posiciones y relaciones de los grupos cobran sentido como socialmente producidas y productoras del orden social.

\section{El impugnado proceso de reorganización territorial}

En el estado de Chiapas, luego de iniciado el levantamiento del EZLN en enero de 1994, las luchas municipalistas han adquirido gran relevancia. Desde que el gobierno federal, a través del negociador Manuel Camacho Solís, propuso la creación de los municipios de Guadalupe Tepeyac en Las Margaritas y Marqués de Comillas y Lacandonia, en Ocosingo, el tema de la remunicipalización del estado sería retomada a lo largo del proceso de negociación y de paz, pero también concretada de facto por las partes en conflicto. En las mesas de negociación de San Andrés Larráinzar (Sacam'chen de los Pobres) la propuesta quedaría asentada en los acuerdos firmados el 16 de febrero de 1996. Suspendido el diálogo en agosto del mismo año, el conflicto entre el EZLN y sus aliados contra el Estado nacional se ha convertido, desde entonces, en una disputa por el control territorial y por el ejercicio de jurisdicción sobre sus recursos (naturales y sociales).

Cabe señalar que la definición weberiana del Estado como órgano burocrático, el cual posee el control de la fuerza física y dicho uso es considerado legítimo por parte de los miembros de la sociedad (Weber, 1984), es poco útil analíticamente en un contexto en donde ambas partes reclaman la legitimidad de sus acciones militares. ${ }^{5} \mathrm{La}$ evidencia etnográfica muestra que, logrado el control territorial, las acciones de cualquiera de las partes en conflicto se concentran en lograr el reconocimiento de sus leyes y gobierno antes que en la coacción, aunque reconozco que la amenaza de la violencia es latente. Por ello, encuentro sugerente las propuestas de la Antropología Política, que en el estudio de sociedades preindustriales sugieren dividir la acción del Estado en los sectores de la administración y de lo político. El primer sector está constituido por el tipo de relaciones de la definición weberiana; mientras que sobre el segundo, Smith (1956) señala que se trata de las acciones dirigidas al ejercicio y la competencia por el poder.

Esta separación de carácter heurístico permite concentrarme en el conjunto de relaciones sociales encaminadas a participar, negociar o imponer las decisiones que afectan a un grupo social, que no están necesariamente arregladas en un contexto formal o institucional; es decir, no tienen un arreglo jerárquico, aunque constituyen formas de organización política. Las acciones de los individuos están dirigidas a ejercer influencia, aunque típicamente dichas acciones recaen en la figura del líder.

Lo que la etnografía del proceso permite adelantar es que se trata de un interjuego de búsquedas de legitimidades y consensos que llevó, en su momento, a la hegemonía de alguna de las agrupaciones aglutinadas en torno a un proyecto de dominación. Estas relaciones sociales constituyen el campo de lo político, y ejercen influencia y son influencias dadas históricamente por las estructuras y las instituciones políticas formales.

En este sentido, el EZLN impulsó la instauración de "municipios rebeldes" en su área de influencia y, posteriormente, los grupos neozapatistas organizados buscaron ejercer tareas de gobierno y hacerse de jurisdicción con la creación de 32 "mu- 
nicipios" y "regiones" autónomas. Aunado a ello, la autollamada "sociedad civil organizada" formó el Consejo Estatal de Organizaciones Indígenas y Campesinas (CEOIC) como parte del esfuerzo colectivo por encontrar mecanismos de representación política en el estado. Dicha organización llamó el 12 de octubre de 1994 a construir un esfuerzo colectivo de autonomía. El 26 de febrero de 1995 se dio a conocer como Regiones Autónomas Pluriétnicas (RAP) en clara sintonía con los esfuerzos zapatistas de salir del tradicional control corporativo del Estado. En el caso de la región, los esfuerzos de zapatistas y de organizaciones de la CEOIC concurrieron en la formación de "Tierra y Libertad". ${ }^{6}$

Por su parte, el H. Congreso del Estado integró, el 3 de mayo de 1996, a través del decreto número 136, la comisión legislativa especial para la reforma municipal, remunicipalización y redistritación del estado a iniciativa del propio gobernador Julio César Ruiz Ferro; no obstante, las diferentes posturas de los partidos políticos representados en la LIX legislatura local, impidieron que la comisión iniciara actividades. Un año después, el Partido de la Revolución Democrática (PRD) impulsó el reinicio de las actividades de la comisión sin obtener mayores resultados.

En condiciones distintas, y con todo el respaldo del gobierno federal, el gobernador interino Roberto Albores Guillén (1998-2000), entre abril y junio de 1998, procedió a ordenar la detención de las autoridades paralelas, así como el desmantelamiento de las instalaciones de los municipios y regiones autónomos. En mayo de ese mismo año, el gobernador anunció una nueva estrategia para "solucionar" el conflicto, misma que incluía aspectos como: a) un proceso de remunicipalización, que comprendía la creación de 33 municipios en el estado; b) impulsar reformas constitucionales y elaborar una ley indígena, c) establecer Juzgados de Paz y Conciliación Indígena en municipios con mayoría indígena y d) atender las demandas sociales de la población. Con estas medidas — entre otras - argumentaba dar cumplimiento a los Acuerdos de San Andrés.

La propuesta de Albores sobre la remunicipalización del estado ha tenido múltiples lecturas y respuestas. Desde la perspectiva del gobierno estatal y sus funcionarios, un importante segmento de la población ha vuelto al "estado de derecho"; aunque causó pugnas faccionales al interior de las fuerzas priistas. El neozapatismo, por su parte, rechazó el proceso y denunció que era una estrategia de "guerra de baja intensidad" con la finalidad de reposicionar a los aliados gubernamentales locales y recuperar zonas que estaban en manos del EZLN (Hidalgo, 1999). A pesar del rechazo "oficial", los diarios locales y nacionales documentaron a grupos de zapatistas que "entregaban armas por paz y desarrollo".

El proceso de remunicipalización fue impugnado. En esta disputa participaron actores de la "sociedad civil organizada", facciones de diversos partidos políticos y el propio EZLN. El conflicto se generó, debido a la creación ex profeso del Consejo y Comisión Estatales de Remunicipalización del Estado de Chiapas (CYCER), encabezados por el gobernador del estado, Roberto Albores y Noé Castañón León, presidente del Tribunal de Justicia en el estado. Es decir, trasladó la responsabilidad que la constitución local otorga al congreso del estado a esas instancias. ${ }^{7}$ También, se discutía la falta de presencia de los representantes del EZLN en las mesas de negociación - como lo marcaban los Acuerdos de San Andrés - y la sesgada participación de 
representantes comunitarios que estaban a favor del proyecto estatal.

El gobierno del estado no fue capaz de dar cumplimiento a su propuesta y tampoco pudo prever sus resultados. La oferta sumó, a los 33 municipios propuestos, poco más de cuarenta iniciativas comunitarias en todo el estado. Los grupos políticos que encabezaban las demandas locales en la región eran aquellos que crecieron a la sombra de su papel como intermediarios. Cultivados en esa sociabilidad política, la opción disponible para ellos se encontraba en continuar con las demandas cuya iniciativa provenía del Estado y su propia sobrevivencia se sustentaba en la vinculación a sus proyectos y redes sociopolíticas; se trataba de grupos cuyas demandas tienen un corte estamental, en el sentido definido por Weber (1984). Mientras tanto los neozapatistas vislumbraban una opción de cambio y continuaban con sus esfuerzos por mantener vivos a sus municipios autónomos.

Finalmente, el 28 de julio de 1999, aparece publicado el decreto en el Periódico Oficial del estado a través del cual se declaró formalmente creados siete nuevos municipios en el estado: Montecristo de Guerrero, San Andrés Duraznal, Aldama, Santiago El Pinar, Benemérito de las Américas, Marqués de Comillas y Maravilla Tenejapa.

\section{Las demandas municipalistas regionales: dos proyectos, una base territorial}

Maravilla Tenejapa fue la propuesta que el gobierno del estado logró consolidar en la región selva fronteriza. En ese territorio los neozapatistas habían instaurado la región autónoma "Tierra y Libertad" con cabecera en Amparo Agua Tinta, misma que fue desmantelada el 1 de mayo de 1998.
Estas fuerzas políticas todavía aparecen en sus discursos, como grupos polarizados. Por un lado, las redes sociopolíticas corporativas del Partido Revolucionario Institucional (PRI), intermediadas en la región por la Unión de Ejidos (UE) "Lagunillas", la organización Solidaridad Campesino Magisterial (SOCAMA) y los grupos locales afiliados a la Confederación Nacional Campesina (CNC). Por el otro, las redes de organizaciones "independientes" que han operado en la región desde la década de los ochenta, y respondieron al llamado autonómico como parte de la "sociedad civil organizada"; entre ellas las organizaciones Lenguas Mayas, Pueblos Indígenas de la Selva, y Educación y Derechos. No obstante, ninguno de los dos constituyó un bloque homogéneo ni un grupo político que pudiera establecer su hegemonía. Antes bien, tenían conflictos faccionales y constantemente negociaban sus propios márgenes de operación y vinculación con los actores regionales, así como el reconocimiento de sus formas de representación política.

Para definir un proyecto de reorganización territorial, autonomía o municipio libre, se encuentran componentes estructurales importantes: los procesos de colonización de la selva y las redes migratorias; las clientelas políticas sustentadas en la forma de tenencia de la tierra: el ejido. Además, las redes sociales y políticas constituidas a partir de formas organizativas para el acceso a financiamiento, estatal o de ONG's internacionales, para diversos proyectos productivos o en aspectos relacionados con el bienestar social (salud, educación, alimentación, etcétera). Estos factores estructuraron el sistema de reciprocidades locales y regionales, además nos permiten reconocer ciertas continuidades históricas en las demandas y sociabilidades políticas que han con- 
formado a los grupos políticos en la microrregión selva fronteriza.

La postura de los grupos políticos ha cambiado en el transcurso de los últimos diez años. Previo al levantamiento zapatista, la hegemonía de las redes clientelares priistas parecía indiscutible a través de la CNC y SOCAMA, principalmente, aunque contando con un importante respaldo de los profesores que vinculaban a las organizaciones locales con la sección VII del Sindicato Nacional de Trabajadores de la Educación (SNTE). ${ }^{9}$ Sin embargo, las fuerzas del EZLN ya estaban organizándose aunque de manera soterrada y sin disputar abiertamente las estructuras de poder local a los priistas. Aún después de 1994, los simpatizantes zapatistas no mostraron un abierto apoyo al EZLN en sus comunidades. ${ }^{10}$ Su presencia fue clara a partir del segundo bimestre de 1994 cuando los comisariados ejidales comandados por ceneceístas y socameros decidieron, a través del mecanismo corporativo de la asamblea ejidal, salir de la región ante el temor de que el conflicto armado se expresara en sus comunidades.

Los grupos de simpatizantes zapatistas dejaron a los priistas salir y tomaron el control de la región. Por medio de acuerdos que firmaron a nombre de "la comunidad", se hicieron del control político ejidal y se pusieron a la cabeza de la representación política en el municipio rebelde "Tierra y Libertad". A pesar del regreso de los desplazados, y siendo los simpatizantes clara minoría en los ejidos, fueron los retornados los que tuvieron que negociar su reinserción en el ejido-comunidad y respetar los acuerdos tomados en su ausencia. En muchos de los casos, la combinación de factores hizo que la población retornada ratificara la pertenencia corporativa al municipio autónomo "Tierra y Libertad".
No obstante, la situación cambió. En un primer momento, la convergencia constitutiva de la autonomía entre zapatistas locales y la "sociedad civil organizada" en torno a la CEOIC, parecía hacer de esta opción una de las posturas políticas más fuertes en la región y su permanencia y cierta legitimidad pareció en un momento incuestionable. “Tierra y Libertad" trastocó el orden territorial y las formas de representación política hegemónicas del "municipio finquero" neamente, la necesidad de producir un nuevo territorio acorde a las necesidades de una región marginada, alejada de su cabecera municipal.

La región autónoma se sustentó en "una demarcación virtual y no territorialmente compacta" (Burguete, 1998), a partir del criterio de adscripción "voluntaria" y el rechazo a la presencia de las agencias del Estado. Su territorio virtual fue variable, ya que se extendía a lo largo de la frontera con Guatemala en las comunidades donde contaba con simpatizantes, aunque no fueran mayoría; en su momento de esplendor cubrió desde el municipio de Ocosingo hasta Tapachula. Contaba con una cabecera municipal en Amparo Agua Tinta y dos delegaciones repartidas en ese extenso territorio, una en Belisario Domínguez y otra en Paso Hondo.

El proyecto de autonomía provocó alianzas y rupturas entre bases zapatistas con simpatizantes afiliados a organizaciones de la CEOIC y/o a la agrupación regional Frente de Organizaciones Campesinas Independientes (FOCI). El principal punto de conflicto se encontraba en que las organizaciones sociales reivindicaban su derecho a exigir al gobierno que cumpliera su papel como financiador del "desarrollo" local, mientras que la dirigencia zapatista mantenía una postura radical en donde la autonomía significaba el rechazo total a esos 
recursos. Los habitantes de "Tierra y Libertad", contrario a los mandos zapatistas de excluir de sus servicios a los que no se reivindicaron como autonomistas, hicieron del mandato "todo para todos" la regla regional, razón por la cual, hasta los priistas que así lo desearan podían acceder a los servicios prestados por el ayuntamiento autónomo, situación que aumentó las fricciones entre las organizaciones independientes que simpatizaban con el proyecto de autonomía y la dirigencia militar del EZLN.

La legitimidad política y el relativo "éxito" del municipio autónomo ${ }^{12}$ se sustentaron, más allá del funcionamiento y de la racionalidad administrativa, en la importancia concedida a tres aspectos centrales de los mecanismos de gestión: 1) la cercanía, reconocimiento y contacto permanente de los "representantes" con los "gobernados". Aquí respetaron sus formas de organización social, que vinculaba niveles de representación desde el ejidocomunidad, pasando por las organizaciones sociales hasta las representaciones regionales; 2) la atención prioritaria a aspectos centrales de la vida cotidiana en la región (salud, educación y proyectos productivos). En este aspecto, impulsaron un discurso de desarrollo sustentable; y, 3) un marco de compromisos de corte moral como integridad, dignidad, respeto a derechos, obligaciones y a la diferencia cultural. Todo ello, al menos en el discurso, se sustentaba en las aspiraciones del avance democrático y ciudadanizador.

El flujo general de las acciones neozapatistas llevó a que muchas de las organizaciones locales de cualquier filiación política apoyaran las demandas del reconocimiento constitucional de la diferenciación étnica y la autonomía. Así, la manera en la que este espacio era concebido, planteó la necesidad de la construcción de un nuevo pacto entre gobierno y sociedad (pluriétnica). En este aspecto el concejo municipal autónomo enfatizaba los esfuerzos por "hacer gobierno" que derivaron en el fortalecimiento de una creciente demanda por el reconocimiento bidireccional del "cuarto ámbito de gobierno", en palabras de un ex presidente del concejo autónomo:

No se trataba ya de qué es la decisión que vamos a tomar como grupo indígena tzotzil, tzeltal o tojolabal. Nos planteamos la pregunta de qué hacer con el caxlan y cómo lograr que entre los hermanos indígenas no se hicieran diferencias. Planteamos que cada ejido tuviera plena libertad para elegir sus representantes y tomar su postura; luego esos representantes harían llegar la palabra de la comunidad para que se tomara en cuenta en el concejo autónomo, que era regional (A. C. ejido La Hoja Seca, 22/03/2002).

La tendencia en el caso que nos ocupa fue la transformación y el fortalecimiento de los mecanismos comunitarios para la toma de decisiones. La tradicional asamblea ejidal en donde los individuos con derechos ejidales (hombres generalmente) tomaban las decisiones que afectan al núcleo de población en su conjunto amplió su espectro de representación al requerir de la participación de hombres y mujeres mayores de edad. Se desconoció a las autoridades municipales y se buscó una representación política regional, la cual trascendía la identificación particular de los grupos indígenas en cada comunidad o ejido.

Mientras tanto, el gobierno del estado y sus redes sociopolíticas en la región impulsaban la creación del municipio libre, que —ahora sírepresentaría los intereses de la población, es decir, sería un municipio indígena. La oferta gubernamental fue abanderada por socama. Desde lue- 
go, el municipio libre se legitimaba bajo las mismas "condiciones objetivas" que observaron los neozapatistas; no obstante los intereses que lo dinamizaban eran distintos. La promesa de una significativa derrama económica para la cabecera municipal, además de las aspiraciones de consolidación de las redes de poder y clientelas específicas del grupo que encabezó la demanda, fueron aspectos que jugaron un papel central en el imaginario colectivo del significado que tendría ser "cabecera municipal".

Con ello, diversas facciones priistas impulsaron fuertemente la creación de municipios libres; socama a favor de Maravilla Tenejapa, el Consejo Productivo Indígena-Campesino de la Selva (COPICAS), una organización propiciada por la dirigencia del programa "Cañadas" y vinculada al grupo político del senador Carlos Rojas, a favor de Nuevo Huixtán. Los profesores afiliados a la sección VII del SNTE identificados del PRI, con el grupo político de Jesús López Constantino y el Partido del Trabajo (РT), buscaban apoyos extralocales para Nuevo San Juan Chamula. Mientras que los grupos de Amparo Agua Tinta esperaban que la promesa estatal se cumpliera y se estableciera la cabecera municipal en su ejido. En tanto, las organizaciones "independientes", como Lenguas Mayas y Pueblos Indígenas de la Selva, que respaldaban la autonomía, otorgaban su apoyo al municipio Nuevo San Juan Chamula. Esta última propuesta fue motivo de convergencias entre neozapatistas y priistas para tratar de enfrentar la propuesta de SOCAMA y ganar adeptos a sus proyectos y el respaldo de sus redes regionales y estatales.

Cada una de las dirigencias locales buscó el apoyo de los ejidos en la región. Esto motivó que tanto la dirigencia a favor de Nuevo Huixtán, como de Nuevo San Juan Chamula, extendieran sus rei- vindicaciones territoriales incluyendo las propuestas del gobierno estatal, Maravilla Tenejapa y Amparo Agua Tinta. El resultado fue la reivindicación de un municipio regional que abarcara a los ejidos fronterizos de los municipios de La Trinitaria, La Independencia, Las Margaritas y Ocosingo. Aunque la propuesta del municipio Maravilla Tenejapa fue cuestionada e impugnada, no sólo por los neozapatistas, como una mala opción ante una historia local de intolerancia y caciquismo priista, ésta obtuvo un respaldo incondicional por parte de los actores políticos estatales debido a que la red política que en esos momentos tenía mayor presencia entre la burocracia estatal y un buen respaldo federal, fue la de SOCAMA. ${ }^{13}$

En este panorama en el cual la hegemonía zapatista estaba fracturada, parecía que socAma saldría fortalecida. Sin embargo, no fueron éstos los que se hicieron del control de la estructura formal de poder local. La capacidad de dirigir y lograr la creación del municipio devino en pírricas victorias para sus dirigentes, el viejo sistema clientelar y aun para nuevas organizaciones sociales que no objetaron la posibilidad de sumarse a la reorganización territorial dirigida. Las redes de socama fueron desestructuradas. Algunos de sus grupos y líderes mantuvieron fuertes lazos con el PRI, pero también sufrió diversas rupturas al interior de sus propias figuras jurídicas, algunos de sus grupos de apoyo decidieron salir del PRI y se afiliaron a otras fuerzas políticas. Aunado a ello, un nuevo pacto de dominación entre las fuerzas políticas estatales y locales favoreció a los ceneceístas. Los líderes de la CNC tomaron el control del Concejo Municipal de Maravilla Tenejapa (1999-2001) designado por el Congreso local.

No podemos negar que la reorganización territorial impulsada bajo la forma de municipio libre 
favoreció la organización y la adquisición de nuevas capacidades de intermediación para grupos particulares en la región. Sin embargo, el poder ganado estuvo dirigido a estructurar de abajo hacia arriba una red de lealtades que garantizaran el éxito del proyecto de remunicipalización estatal. $\mathrm{El}$ proceso de toma de decisiones de las "asambleas ejidales", que en su mayoría habían aceptado la ampliación de representación planteada por los neozapatitas, fue un instrumento que se utilizó no para que las poblaciones ejidales decidieran sobre su desarrollo, sino para asegurarse que aceptaran, sin los cuestionamientos propios de la democracia, el derrotero fijado verticalmente desde el proyecto gubernamental.

Existieron las redes políticas de carácter regional que estuvieron dispuestas a mediar con la población local buscando que se adhirieran a una - y sólo una - forma de organización políticoterritorial. La particularidad de esta región fue que, a pesar de las significativas diferencias ideológicas y de filiaciones políticas, poco a poco, los grupos dejaron las posturas polarizadas a favor del municipio autónomo versus municipio libre. La convergencia se situó en el espacio municipal.

\section{Las disputas por el ayuntamiento ¿continuidad o cambio?}

El resultado de las disputas por la reorganización territorial en la región llevó al recorte y la focalización de los conflictos políticos en un nuevo espacio. Las principales organizaciones y sus líderes han orientado sus acciones a lograr influencia en los procesos de toma de decisiones y hacerse del control de los puestos de autoridad en el ayuntamiento, sin perder presencia fuera de los nuevos límites municipales; es decir, las relaciones de poder de los grupos que encabezan dichos conflictos mantienen su carácter regional.

Ahora, como en el pasado, son las organizaciones sociales (uniones de ejidos, sociedades de solidaridad social, de productores rurales, asociaciones rurales de interés colectivo, etcétera) las que conforman las redes de poder local y regional. Estas redes se consolidaron al haber operado y mediado de manera informal los programas estatales (implementación de proyectos productivos, atención a salud, educación, etcétera). Son entonces estas formas organizativas, que agrupan a individuos de diferentes ejidos, las que se usan por parte de los pobladores del municipio para identificarse como parte de una grupalidad - con su ideología y filiaciones políticas particulares - en una relación (algunas veces antagónicas) frente a otra u otras.

Estas redes y sociabilidades políticas son usadas en diversos intentos por imponer un proyecto de dominación. Con ello, las relaciones sociales son imaginadas como una escala entre niveles verticales de articulación y estamentos horizontales de integración a partir de las prácticas clientelares; es decir, cada líder y "su grupo" configuran una asociación política sustentada en demandas estamentales (Weber, 1984) dada su postura como indígenas-campesinos, en donde al menos idealmente, las relaciones sociales se desarrollan cara a cara entre miembros de diversos ejidos y tienen un carácter recíproco e igualitario; una economía mora ${ }^{14}$ con articulaciones jerárquicas hacia otros grupos en el ámbito estatal.

Una vez instaurado el municipio libre de Maravilla Tenejapa, las fuerzas políticas regionales buscaron posicionarse en el nodo de relaciones políticas que atraviesan por el ayuntamiento y ejercer influencia en las decisiones que se tomaban. No 
obstante, en el campo político las autoridades designadas instrumentaron, antes que la búsqueda de consensos, un juego de "suma cero"; es decir, las nuevas reglas eran que el grupo ceneceísta, que se había hecho del control político del concejo municipal, ganaba todo y favorecía exclusivamente a sus propias clientelas políticas.

Ante la postura asumida por la dirigencia ceneceísta en el concejo municipal, las principales organizaciones sociales como la UE Lagunillas, Lenguas Mayas, Pueblos Indígenas de la Selva y copicas iniciaron un lento proceso de convergencias en torno a las demandas de corte municipalistas. Su demanda principal fue contar, como organizaciones, con espacios para la participación en procesos de toma de decisiones propios del concejo municipal, tales como la aplicación y operación de los recursos del ramo 33 y del programa "Cañadas", ahora programa de desarrollo integral de la selva Lacandona. Nuevamente el argumento central para legitimar sus demandas fue plantearla como una "respuesta" a las necesidades de los 'compañeros' indígenas-campesinos de la región.

En alianza con las autoridades locales ${ }^{15}$, o aun a pesar de ellas, dichos grupos han intentado mantener bajo su control, con la figura de proyectos "productivos", los recursos provenientes de la federación que pueden o no atravesar por las arcas municipales. Desde luego, mantener un acceso privilegiado a dichos recursos (principalmente los fondos compensatorios operados en el programa "Cañadas" y SEDESOL) dependió de las redes de relaciones en las que se insertaban cada una de las organizaciones y sus líderes.

Los controles instaurados por las políticas del Estado en el ejercicio fiscal del año 2000, tendientes a reforzar el federalismo, fueron el instrumento que la facción ceneceísta utilizó para favorecer a sus clientelas. Los ayuntamientos, a partir de dicho año, tuvieron que supervisar el uso de los recursos del programa "Cañadas"; el presidente municipal tenía que firmar todas las solicitudes de recursos, mismos que, una vez aprobados los proyectos, eran ingresados a las arcas municipales. Bajo estas condiciones pudieron exitosamente allanar el camino a las solicitudes de sus clientelas e impedir el reparto de recursos a otros grupos.

socama, copicas y Pueblos Indígenas de la Selva vieron afectados sus intereses. Gracias a la articulación de sus líderes con la burocracia estatal, lograron que algunos de sus proyectos fueran aprobados y contaran con recursos. En algunos casos, éstos fueron entregados por las dependencias federales directamente a las organizaciones; no obstante, en otros — siguiendo la normatividadfueron entregados al ayuntamiento. Las autoridades resistieron la tentación de un hacer uso discrecional de los mismos. Al ser recursos de los llamados "etiquetados", los entregaron a los beneficiarios; sin embargo, no perdieron la oportunidad para mostrarse como un gobierno eficiente y además ganar en legitimidad al aclarar que los recursos provenían del ayuntamiento, no de las organizaciones y que esa sería la regla en el futuro.

Los grupos políticos afiliados al concejo municipal parecían tener condiciones inmejorables para imponer su hegemonía. No obstante, sus acciones fueron contestadas por las organizaciones sociales, quienes ejercieron presión a través de la movilización conjunta. Estas organizaciones que defendían proyectos políticos diferentes e incluso antagónicos, aparecieron en la escena política del municipio recientemente constituido, como un bloque de alianzas en defensa del derecho de los "ciudadanos" a intervenir en los asuntos públicos. 
En el campo político local, estos procesos impactaron en los liderazgos. Algunos, ligados al concejo municipal, se consolidaron; otros, aunque vinculados a las organizaciones priistas, perdieron terreno. Mientras que al interior de las organizaciones independientes ocurrió un paradójico resultado. Por una parte, se consolidaron y lograron disputar exitosamente recursos para sus proyectos, aunque con el descrédito de sus aliados en el neozapatismo regional al verse obligados a negociar con el ayuntamiento; por la otra, se debilitaron y fragmentaron en términos de su influencia regional, aunque crecieron en legitimidad y mantuvieron proyectos locales con financiamiento proveniente de los "solidarios" nacionales e internacionales. La posición que cada uno de ellos ocupó, dependió de un fuerte vínculo personal con sus seguidores y el éxito o no de sus iniciativas. Éstas dependían de los "buenos contactos" hacia otros niveles de articulación y su propia capacidad de negociación, es decir, como señala Guillermo de la Peña (1986), este tipo de líderes también cuenta con su espacio de autonomía. Es en ese margen en donde encontramos acciones que convienen a los actores locales aunque contravengan las directrices de las organizaciones nacionales.

El ayuntamiento de Maravilla Tenejapa fue, entonces, la concreción de ese nodo de relaciones de las grupalidades de signo político distinto. La administración municipal y las diversas concepciones que los actores locales tienen de un "buen gobierno", son los espacios o arena política (Swartz, Tuden y Turner, 1966) en donde los grupos han entrado en una etapa distinta de confrontaciones y negociaciones. Esta etapa se caracteriza por las relaciones cara a cara, las disputas por acceder al manejo y control de recursos, pero también por el impulso a la participación ciudadana en el ámbito municipal. El discurso por la autonomía es apropiado indistintamente por las diferentes grupalidades a favor de la defensa de los derechos de los "indígenas campesinos", para tratar de adelantar o imponer un proyecto de dominio que configura el campo político.

Las acciones del concejo municipal tuvieron un contrapeso en las organizaciones sociales que mantuvieron una vigilante atención a las acciones del mismo. La amenaza de la consolidación de este bloque de alianzas políticas provocó diversas estrategias para su desestructuración. La convergencia llegó a aglutinar a más de cuarenta grupos de la región. Ello motivó que, ante cada convocatoria a reuniones, se sirviera de la amenaza del uso, y la presencia real, de la fuerza pública estatal; pero también se buscó favorecer a pequeños grupos con recursos municipales para que abandonaran sus movilizaciones. Esta última estrategia benefició principalmente a las organizaciones afiliadas a COPICAS.

La elección local de octubre de 2001 y su resultado fue una continuación de los reacomodos de las fuerzas políticas locales y regionales. Desde el ascenso de Pablo Salazar a la gubernatura, por la vía de una alianza opositora al PRI, se abrieron nuevas opciones para las fuerzas políticas locales. Las organizaciones sociales de filiación neozapatista, al lado del PRD, parecían las mejor posicionadas ante el relevo en el gobierno estatal. Efectivamente, estas organizaciones dejaron de percibir el bloqueo a sus proyectos instrumentado desde el concejo municipal. El ambiente político en todo el estado se sobrecargó de expectativas que devino en algunas desilusiones. En la región, el PRD y sus aliados esperaban contar con las condiciones para ganar la elección local.

No obstante, acaeció el triunfo del PRI. Esto fue posible gracias a la combinación de diversos 
factores. El principal de ellos fue la fragmentación de las fuerzas políticas, que cinco años antes parecían dos bloques contrapuestos. En dicho proceso SOCAMA se fracturó. La dirigencia de la UE Lagunillas abandonó las filas priistas y entró a la competencia electoral al lado de la dirigencia de Lenguas Mayas bajo las siglas del PRD. El asesor regional de SOCAMA abandonó las filas priistas al no ser electo como candidato por ese instituto político a la presidencia municipal y al lado de algunos de sus seguidores de la UE Lagunillas contendió bajo las siglas del Partido Alianza Social (PAS).

En este reacomodo de las fuerzas políticas locales bajo las condiciones del proceso electoral, se asegura que los zapatistas participaron en apoyo a los candidatos del PRD, pero que algunos neozapatistas prefirieron hacerlo a favor del candidato del PAS. No obstante, por sorprendente que parezca, quien fuera el presidente del comité local para el proceso de remunicipalización, también de extracción priista, aseguró que una parte de los zapatistas "bien entendidos" apoyaron al candidato del Partido Acción Nacional (PAN).

En la elección de autoridades municipales, aunque se respetó la competencia electoral partidaria y la relación un individuo un voto, la mediación se realizó antes que por la vía de los partidos políticos con las organizaciones sociales. El proceso en sí mismo no fue impugnado. Sin embargo, se suscitaron conflictos postelectorales, a raíz de la iniciativa del presidente municipal electo quien comunicó a los regidores plurinominales que su presencia no será requerida en el cabildo municipal. ${ }^{16}$

Aceptar la participación de dos regidores plurinominales hubiera resultado más satisfactorio para los grupos priistas locales que no pudieron prever el impacto de la iniciativa del presidente electo. Las organizaciones sociales siguie- ron el llamado de los líderes y se sumaron a la iniciativa los partidos políticos que impugnaron la arbitraria decisión. Mientras las direcciones estatales de los partidos políticos recomendaban a las municipales esperar la intervención y resolución del Tribunal Estatal Electoral (TEE), las organizaciones sociales tomaron otra iniciativa. $\mathrm{Al}$ existir una instancia comunitaria de conciliación, creada por el gobierno de Albores en el marco de la remunicipalización, el juzgado de paz y conciliación indígena, convocaron a una reunión para discutir un nuevo acuerdo.

Las instalaciones fueron tomadas con el presidente electo en su interior. Después de dos días de negociaciones, en los que nadie pudo salir de las instalaciones del juzgado, se llegó al acuerdo de que, en el mismo porcentaje obtenido en la elección, los partidos repartirían los puestos de dirección y empleos pagados por el ayuntamiento entre sus aliados. Asimismo, los priistas tuvieron que aceptar un acuerdo interno a través del cual se repartía, de manera equitativa, el monto originalmente asignado para cinco regidores (tres regidores de mayoría relativa y dos plurinominales), entre siete regidores, con la finalidad de dar entrada al cabildo a los representantes de todas las fuerzas políticas del municipio.

Este sorpresivo resultado fue mediado y sancionado por la Secretaría de Gobierno del estado y no por el TEE. Aparentemente instituyó un muy loable pluralismo en esta arena política en particular. No obstante, dicho resultado en un lugar que se ha caracterizado por su priismo de viejo cuño (corporativo y autoritario) se explica, en parte, por la voluntad del gobierno estatal para terminar con una práctica política de años trillado en el estado: la toma del ayuntamiento por las organizaciones, la declaración de destitución del mismo por el Congreso 
estatal, la negociación de las partes en pugna mediadas por legisladores y el propio ejecutivo para, posteriormente, instaurar concejos municipales.

Caracterizar, en una resumida conclusión, al proceso general de la transformación territorial y sus impactos en las relaciones políticas en términos de un puro racionalismo instrumental, situaría a ambas partes en una muy mala posición en el espectro del campo político. La facción ceneceísta se ha mantenido al frente de la administración municipal y ha pretendido mantener una imagen de continuidad en un dominio, formalmente indisputado del PRI sobre la administración municipal. A través de ello el PRI podría argumentar su control político sobre la región. En otra parte del espectro, el neozapatismo podría argumentar que logró, a pesar de una cabecera municipal autónoma desmantelada y una larga negociación para la liberación de presos políticos, el acceso a puestos y presupuestos. No obstante, éstos estuvieron dentro de las formas reconocidas por el Estado y no en las estrategias propuestas por el EZLN, una política de dos caras. ${ }^{17}$

Una conclusión de este tipo, además de presentar una muy burda imagen de los actores sociales y anclarse en la idea de grupalidades políticas polarizadas, no daría cuenta de las aceleradas transformaciones que vive el campo político. Fragmentaciones de grupos, faccionalismo y reacomodo de las fuerzas políticas, ha sido la constante en el tiempo reciente. Aun la territorialidad regional analizada es discontinua y fraccionada. Los alcances y limitaciones jurídicas de la remunicipalización están por evaluarse. Desde el ámbito local los propios límites territoriales del municipio están aún siendo impugnados ${ }^{18}$ y los significados asignados al territorio (municipal y regional) aún son confusos.
Por ello, me parece pertinente enfatizar las trasformaciones en el campo de lo político y señalar que todas estas transformaciones, conflictos, pugnas y negociaciones que han impactado sobre la posición que ocupan los grupos políticos dependen de un situación particular históricamente desarrollada. Es allí en donde actualmente resulta central el desarrollo de múltiples confrontaciones por el control del ayuntamiento, entre grupos de extracción política heterogénea y cambiante. Aunado a ello, la construcción identitaria de los indígenas-campesinos ha sido el instrumento para manejar la diferencia y presencia de diversos grupos étnicos y su derecho a participar en las acciones tomadas por el ayuntamiento.

El municipio, como una arena política ha abierto, al lado de la demanda y ejercicio de la autonomía, nuevos espacios de participación y representación política. Es decir, la construcción identitaria a la que se ha hecho referencia otorga los contenidos étnicos que aparecen ya como signos de subordinación o como símbolos de resistencia (Comaroff y Comaroff; 1992) en las disputas por la ciudadanía.

\section{Reflexiones finales}

En el análisis de los sucesos que llevaron a la reorganización territorial y los reacomodos políticos posteriores encuentro la reiterada legitimación de las acciones políticas en nombre de los "indígenas-campesinos" que habitan la región. Esto me lleva a la reflexión sobre el papel que tienen las identidades en el campo político. El uso de las identidades ha permitido la multiplicación de las demandas por los derechos políticos de los indígenas y, en este caso, los logros se han centrado en la apropiación de las políticas sociales por parte de las redes locales que elevaban 
demandas desde su identidad como "indígenascampesinos".

Asumo que la imbricación entre lo étnico y lo político en la demanda de una nueva ciudadanía con derechos diferenciados no es el resultado de esencias culturales irreductibles, ni el resultado de la vinculación local-global de una "revuelta popular posmoderna" que lucha en contra de un Estado hegemónico. Los procesos autonómicos con sus demarcaciones virtuales se deben entender como "comunidades imaginadas" (Anderson, 1983) en un proceso de diálogo y reacomodo con otros procesos. Un reto en particular es el comprender la manera en la cual los proyectos políticos se encuentran, enfrentan y compenetran en el campo político local. Es decir, explicar los elementos que a partir de una identidad "indígena" de la población entran al escenario político, los cuales son "mostrados, manipulados o ignorados de acuerdo con las demandas de una situación particular [...] y manipulan a otros individuos o situaciones con la finalidad de lograr lo que perciben como un contexto más deseable para sí mismos" (Peterson, 1986).

Paradójicamente en la fase de la globalización y la desterritorialización, la búsqueda de esos contextos más deseables entre los grupos étnicos de Chiapas y del país han estimulado, como se muestra aquí, el desarrollo de dos procesos imbricados que centran el interés en el territorio y lo local. Por un lado, proliferan y se radicalizan los cuestionamientos de la estructura político territorial del estado-nación protagonizados por diferentes colectivos étnicos que claman por establecer nuevas relaciones socioespaciales en virtud de las diferencias culturales y étnicas. Por el otro, crece la demanda de reestructuración y democratización de los espacios locales como ga- rantes de la representación y defensa de los intereses de los "ciudadanos".

Son estos reacomodos dirigidos a lograr contextos más deseables para la legitimación de sus propias demandas, lo que Guillermo de la Peña (1996) ha denominado "ciudadanía étnica" que agregan a los derechos de ciudadanía definidos por el sociólogo T. H. Marshall ${ }^{19}$ (1975), la dimensión de los derechos culturales, es decir, a la diferencia. Al respecto Turner (1992), encuentra que el aspecto crítico a la teoría de Marshall es la visión evolucionista de la aparición de los derechos de ciudadanía, pero que en su desarrollo histórico estos derechos efectivamente son "culturalmente organizados" e implican la noción de "participación política y membresía". Con ello, Turner reconoce que las luchas contemporáneas por la ciudadanía "necesariamente involucran problemas de la identidad nacional y la formación del Estado en un contexto de multiculturalismo y pluralismo étnico". Sobre esta argumentación observo a la etnicidad y a la ciudadanía como nuevos espacios de representación y participación política, en una región periférica del conflicto, como los ejes centrales sobre los cuales se han montado las demandas por la autonomía y la municipalización en la selva chiapaneca que centra su interés en el territorio.

Estos derechos políticos eran reforzados por la defensa de los derechos culturales que los neozapatistas enarbolaban. La cercanía de las autoridades se sustentaba en representantes comunitarios extraídos de entre aquellos destacados por su "servicio". Así era como se defendían los principios de membresía a esa "comunidad imaginada", en donde la participación, tal como afirma un dirigente neozapatista, se realizaba "a través de la ley de mandar obedeciendo". 
Para los priistas de la región, los efectos positivos del neozapatismo fueron abrirle los ojos a los "indígena-campesinos" respecto a sus derechos y motivar una renovada presencia del Estado y de la atención internacional. Precisamente, fue este aspecto de la "dignidad" indígena lo que los priistas tradujeron a su horizonte cultural para legitimar sus propias acciones. No obstante, a diferencia de los neozapatistas que argumentaron sus derechos políticos para arribar a la defensa de los derechos culturales, los priistas introdujeron la defensa de los derechos sociales como punta de lanza para respaldar su demanda política del municipio libre y reforzar su papel de intermediarios con sus clientelas políticas. Es decir, demandaron - principalmente"seguridad" y "bienestar" a un Estado que no podía garantizar del todo ambas condiciones, por lo que apareció como "natural", ante el argumento de la lejanía de las comunidades y el contexto de conflicto armado, la necesidad de defender algunos derechos políticos y demandar la reorganización territorial.

$\mathrm{El}$ análisis de las relaciones entre estos dos grupos políticamente diferenciados, más allá de las simples apariencias donde aparecen polarizados, se encuentran facciones políticas que muestran la complejidad de los procesos locales y la reapropiación y reinterpretación de los discursos "oficiales", neozapatistas y del Estado, con la finalidad de obtener ventajas en las luchas políticas locales y con ello consolidar, redefinir o simplemente, mostrar sus signos identitarios como "indígenas-campesinos". Son estas facciones las que disputan de manera dinámica el acceso al poder local durante el proceso analizado y las que, en sus encuentros y desencuentros, han cambiado la estructura y el campo locales de poder.
Luego de la remunicipalización, los grupos locales han propugnado - aun sin una declaración explícita- por una mayor autonomía y con ello han redescubierto una parte, al menos, de los derechos de "ciudadanía" entre los indígenas de la región selva-fronteriza del estado de Chiapas, justo en los márgenes de la "zona de conflicto". En el contexto nacional, con las múltiples vinculaciones globales que el neozapatismo ha logrado, se demuestra que la etnicidad, en su actual protagonismo, constituye una variable importante para comprender el sentido y las características de los cambios sociales de los últimos años en Chiapas y, quizás, reafirmar, desde los procesos locales, la hipótesis central de Huntington (1997) acerca de que la cultura y las identidades están configurando las pautas de cohesión, desintegración y conflicto en el mundo de la postguerra.

Aunque el análisis de las acciones en el municipio de reciente instauración nos dejen con un sabor amargo respecto a la "escuela de la democracia" y mucho que desear respecto a la consolidación desde lo local de un "Estado de derecho", sin duda alguna las relaciones y reacomodos de los grupos en el campo político descrito - en sus relaciones entre lo local, lo nacional y lo global—, depararán transformaciones en las formas que se asumen en el ejercicio del poder, todos ellos, problemas centrales de la democracia. Un asunto sobre el cual vale la pena seguir indagando.

\section{Notas}

${ }^{1}$ Algunas ideas preliminares de este ensayo fueron expuestas en junio de 2001 en el marco del Seminario-Taller Descentralización, municipalización e identidades locales, organizado por El Colegio de Michoacán. La información de campo fue recopilada en el marco del proyecto de investigación Los nuevos municipios en Chiapas. Un análisis de coyuntura CIESAS- 
Sureste con el auspicio de la Fundación Ford. Las ideas expresadas, desde luego, son responsabilidad del autor. Ultima versión, marzo de 2003.

${ }^{2}$ Agradezco a Jorge Morales Nájera el apoyo en la realización de entrevistas.

${ }^{3}$ Retomo la sugerencia de Leyva (1999) respecto a distinguir entre las actividades militares del EZLN o zapatismo, y las acciones políticas de éste y sus simpatizantes o neozapatismo. ${ }^{4}$ La microrregión la nomino a partir de criterios fisiográficos (la selva) y limítrofes (la frontera). La definición social se caracteriza por los procesos de poblamiento donde sociedades indígenas y rurales con características culturales, sociales y políticas diversas, compartieron experiencias económicas y migratorias hacia parte de los municipios de Ocosingo, Las Margaritas y La Independencia ( $c f r$. Acevedo, 1992; Garza, Paz, Ruiz y Calvo, 1994; Leyva, 1994 y 1998; Leyva y Ascencio; 1996, Martner, 1998; y Paz, 1989 quienes documentan, de manera fragmentada diversos aspectos de los procesos sociales que conforman a la región).

${ }^{5}$ Su uso me podría llevar a un análisis donde el énfasis estaría en la militarización de zona y a la caracterización de las estrategias de las partes en conflicto, para instaurar la hegemonía de sus huestes.

${ }^{6}$ Lomelí (1999), realiza un análisis de la RAP "Tierra y Libertad". Mi propio análisis del proceso autonómico regional y la caracterización de sus etapas se encuentra en "Tierra y Libertad": acciones neozapatistas en la selva fronteriza de Chiapas. ¿Expresiones locales en la construcción del "cuarto piso de gobierno"? - en prensa.

${ }^{7}$ Razón por la cual, una funcionaria de la Secretaría de Gobierno del Estado encabezado por Pablo Salazar señaló que a la fecha, en oposición a la remunicipalización de Albores, se podría solicitar la revocación del decreto de creación de los nuevos municipios a través de una controversia constitucional. ${ }^{8}$ Siguiendo los principios de la ética antropológica los nombres de informantes clave (propios, lugares y organizaciones) que aparecen en cursivas, son ficticios. No obstante los contextos y situaciones descritas son reales. Se hace excepción para personajes públicos.

${ }^{9}$ Los profesores de la Dirección de Educación Indígena de la Secretaría de Educación Pública se han convertido en verdaderos líderes locales y regionales. $\mathrm{Al}$ ser los conocedores del castilla se han convertido en asesores en la constitución de los núcleos ejidales, la formación de organizaciones como
Uniones de Ejido para acceder al crédito gubernamental y organizaciones no gubernamentales; aunque carecen de un puesto formal, han concentrado autoridad e influencia en las comunidades de la región. No obstante, como grupo o "categoría" social no se ha indagado a profundidad en la investigación social su papel en el campo de las relaciones políticas en esta microrregión.

${ }^{10}$ Es conocido que las principales batallas, militares y mediáticas se estaban dando en las cabeceras municipales de Las Margaritas, Altamirano, Ocosingo y San Cristóbal de Las Casas. ${ }^{11}$ Municipios con población mayoritariamente indígena, pero dominados por mestizos, la clase pudiente, identificada con formas de producción y reproducción económica y cultural sustentada en la gran propiedad rural (Toledo; 2002). Para la región que nos ocupa "fincas" monocultivadoras de café hasta la década de los ochenta, cuando inicia un proceso de diversificación agrícola y el despegue del auge ganadero.

${ }^{12} \mathrm{He}$ documentado que tanto autonomistas como priistas mantuvieron una doble estrategia. A la par realizaban sus trámites ante las autoridades autónomas y ante las autoridades gubernamentales para acatar la resolución que más convenía a sus intereses.

${ }^{13}$ El regional, el profesor Ernesto Maldonado, viajó a la Ciudad de México para entrevistarse con Elba Esther Gordillo; Manuel Hernández, dirigente estatal, hacía lo propio con el gobernador del estado y Samuel Sánchez, Manuel Sánchez y Jacobo Nazar, diputados locales afiliados a esa organización daban seguimiento a la demanda a través del acompañamiento a los dirigentes locales en cada audiencia que tenían con el licenciado Noé Castañón, presidente del Comité Estatal para la Remunicipalización.

${ }^{14}$ Scott (1976) proporciona la noción de economía moral a la cual recurro, a pesar de las diferencias en los estudios de caso. Esta noción me permite reconocer que existe objetivamente un mundo de desigualdades y jerarquías entre las diferentes grupalidades y ejidos que conforman la región, pero en coyunturas particulares existe una noción de equilibrios intercomunitarios e intergrupales que se deben mantener para potenciar las capacidades de aquellos que buscan recursos frescos, aunque la obtención de estos recursos es desigual y coadyuva a perpetuar ese sistema de desigualdades a nivel intercomunal. A este ámbito permea la idea acerca de la legitimidad de dicho intercambio y se espera reciprocidad bajo otras condiciones. 
${ }^{15}$ La expresión "autoridades locales" alude a un complejo sistema de representaciones políticas, formales e informales, que van desde los comisariados ejidales, los agentes municipales, los ancianos de las iglesias, las personas de prestigio en cada ejido —en función de su acumulación de riqueza, educación o relaciones-, líderes de asociaciones hasta la presidencia municipal y sus variables dependencias y aun el delegado regional de la Secretaría de Gobierno del estado.

${ }^{16}$ Práctica muy extendida en Chiapas que ha provocado violentos enfrentamientos, los cuales culminan engrosando las estadísticas de muertes por razones políticas en el estado. ${ }^{17}$ Un discurso de izquierda pero una práctica progobiernista financiada con dinero del mismo Estado ( $c f r$. Harvey 1998). ${ }^{18}$ El decreto señala que el municipio de Maravilla Tenejapa se formó por treinta ejidos desprendidos íntegramente de Las Margaritas, no obstante, la autoadscripción de los propios ejidos y la información de la Secretaria de la Reforma Agraria indican que diez de ellos pertenecían al municipio de Ocosingo. No existe en el decreto una sola referencia geográfica precisa, que permita dibujar el polígono del municipio. Los trabajos cartográficos, siguiendo trabajo en campo y las orientaciones y distancias ofrecidas por el decreto, resultan en un polígono que no contiene a las treinta localidades del decreto y su figura es distinta al dibujo oficial del gobierno estatal. Se habla de grupo de ejidos de Las Margaritas y de Ocosingo que son "anexos" del municipio creado; además algunos núcleos ejidales que habían rechazado sumarse a la remunicipalización ahora "exigen" al gobierno del estado se reconozca su integración a Maravilla Tenejapa.

${ }^{19}$ Según él, los Estados modernos promueven primero los derechos civiles (libertad de asociación, de palabra, de culto, inviolabilidad de la persona y los bienes, habeas corpus, entre otros), luego los derechos políticos (sufragio universal y seguro, amplio acceso a la representación y al ejercicio del poder, legalidad de los partidos, etcétera) y, por último, los derechos sociales (bienestar, seguridad, educación, salud, protección del trabajo, etcétera) (Marshall; 1975:71-83).

\section{Bibliografía}

Acevedo, M., 1992, Margaritas: una experiencia de frontera. Tesis presentada para obtener el grado de Maestría en Estudios Regionales, Instituto Mora, México.
Anderson, B, 1983, Imagined communities, London, Verso. Bourdieu, P., 1990, "Espacio social y génesis de las 'clases", en: Sociología y cultura, Grijalbo-CONACULTA, México, pp. 281-309. Burguete Cal y Mayor, Araceli, 1998, "Remuncipalización en Chiapas: los retos", en: Memoria. Revista mensual de política y cultura, Núm. 114, agosto de 1998, CEMOs, México, pp-14-25. Comaroff, J. y J. Comaroff, 1992, Ethnography and the Historical Imagination. Boulder, CO: Westview Press.

De la Peña, G., 1986, "Poder local, Poder regional: perspectivas antropológicas” en: Vanneph, A. y J. Padua, Poder local, Poder regional, El Colegio de México-CEMCA, México.

—, 1996, 'Notas preliminares sobre la 'ciudadanía étnica' (el caso de México)", en: Olvera, A. (coord.) La sociedad civil, de la teoría a la realidad, El Colegio de México, México.

Garza, A. M., M. F. Paz, J. M. Ruiz, y A. Calvo, 1994, Voces de la Historia. Nuevo San Juan Chamula, Nuevo Huixtán, Nuevo Matram, CRIM, UNAM, México.

Harvey, N., 1998, The Chiapas Rebellion. The struggle for land and democracy, Duke University Press, USA.

Hidalgo, O., 1999, "La otra cara de la remunicipalización", en: Chiapas al día, Boletín CIEPAC, núm. 153, 29 de abril de 1999, México.

Huntington, S., 1997, El choque de civilizaciones y la reconfiguración del orden mundial, Piadós, Buenos Aires /Barcelona.

Leyva, X., 1994, "Hacia el Ahlan K'inal”, en: Armendáriz, M. L. (comp.), Chiapas, una radiografía, FCE, México.

—, 1998, "Catequistas, misioneros y tradiciones en las Cañadas”, en: Viqueira, J. P. y M. H. Ruz (eds.), Chiapas. Los rumbos de otra historia, UNAM, CIESAS, CEMCA, U. de G., México. —, 1999, "De las cañadas a Europa: niveles, actores y discursos del nuevo movimiento zapatista (NMz) (1994-1997)", en: Desacatos. Revista de Antropología Social. Núm. 1, primavera de 1999, CIESAS, México.

—, y G. Ascencio, 1996, Lacandonia al filo del agua, CIESAS, FCE, México.

Lomelí, A., 1999, "Pueblos indios y autonomías zapatistas", en: Burguete, A. México: experiencias de autonomía indígena. Grupo Internacional de Trabajo sobre Asuntos Indígenas, Documento IWGIA, núm. 28, México.

Marshall, T. H, 1965, Class, Citizenship and Social Development, Anchor Books, New York.

Martner, D., 1998, La producción agroecológica. Una alternativa de desarrollo sustentable para la microrregión fronteriza selva. Tesis de Maestría en Ciencias en Desarrollo Rural Regional, Univer- 
sidad Autónoma de Chapingo, México.

Paz, M. F., 1989, La Migración a Las Margaritas: una historia a dos Voces. Tesis para obtener el grado de licenciada en Antropología Social, Universidad Autónoma de Chiapas, México. Peterson, A., 1982, Ethnic Identity. Strategies of Diversity, Indiana University Press, USA.

Rodríguez, L., (en prensa). “Tierra y Libertad”: acciones neozapatistas en la selva fronteriza de Chiapas. ¿Expresiones locales en la construcción del "cuarto piso de gobierno"?, en: Anuario 2001, CESMECA-UnICACH, México.

Scott, J., 1976, The moral economy of the peasant: Rebellion and resistance in Southeast Asia. New Haven. Yale University Press. Smith, M. G., 1956, "Segmentary Lineage Systems" in: Journal of the Royal Anthropological Institute, núm. 86, 39-80.
Swarts, M., V. Turner \& A. Tuden (eds.), 1966, Political Anthopology, Aldine Publishing Company, EUA.

Turner, B., 1992, “Outline of a Theory of Citizenship", in: Moufe, Ch. (Ed.). Dimensions of Radical Democracy. Pluralism, Citizenship, Community, Verso, Great Britain.

Toledo, S., 2002, Fincas y Poder en Simojovel Chiapas, UNACH, México.

Velázquez, E., 1997, “La apropiación del espacio entre nahuas y popolucas de la Sierra de Santa Marta, Veracruz", en: Hoffmann, O. y F. Salmeron, Nueve estudios sobre el espacio. Representación y formas de apropiación, Ciesas-Orsom, México. pp. 113-128.

Weber, M, 1984, Economía y Sociedad, FCE, México. 